\title{
Genetic risk of Alzheimer's disease:
}

\section{advising relatives}

\author{
M. B. LIDDELL, S. LOVESTONE and M. J. OWEN
}

\begin{abstract}
Background Clinicians are increasingly asked by relatives of patients with Alzheimer's disease to advise on their genetic risk of developing Alzheimer's disease in later life. Many clinicians find this a difficult question to answer.
\end{abstract}

Aims To provide information for old age psychiatrists wishing to advise relatives of their risk of developing Alzheimer's disease.

Method A selective review of the key literature on the genetic epidemiology of Alzheimer's disease.

\section{Results Currently a DNA diagnosis is} attainable in some $70 \%$ of families with autosomal dominant Alzheimer's disease. In first-degree relatives of most cases, risk is increased some three- or four-fold relative to controls, but only one-third of this is realised in the average life span. Apolipoprotein E genotyping cannot be used as a predictive test and confers only minimal diagnostic benefit.

\section{Conclusions Pedigrees with familial Alzheimer's disease should be referred to a Regional Centre for Medical Genetics. Accurate risk prediction is not possible in the vast majority of pedigrees with Alzheimer's disease, although it is possible for the psychiatrist to give a rough estimate of the risk, which can reasonably the couched in reassuring terms.}

\section{Declaration of interest None.}

Eighty per cent of a typical old age psychiatrist's time is spent in the assessment and management of dementia. Most of this is due to Alzheimer's disease or a combination of Alzheimer's disease and vascular dementia. Because of increased public awareness of advances in genetics and the efforts of advocacy groups in explaining the latest research findings, relatives of people with Alzheimer's disease are increasingly asking the question, "What is my risk and what is my children's risk of developing Alzheimer's disease?". The aim of this article is to summarise the relevant research and to suggest ways in which this can be answered.

\section{AUTOSOMAL DOMINANT FAMILIAL ALZHEIMER'S DISEASE}

Most of the highly publicised advances in the genetics of Alzheimer's disease have concerned those very rare families with autosomal dominant forms of the disease, so-called familial Alzheimer's disease (FAD) kindred, in which $50 \%$ of each generation, regardless of gender, succumb to Alzheimer's disease, usually by early midlife (reviewed by Selkoe, 1999). The identification of causative mutations within the amyloid precursor protein (APP) and presenilin genes (PSEN1 and PSEN2) has probably overinflated the public's perception of the role of genes in causing the far more common forms of Alzheimer's disease that do not show autosomal dominant transmission. Yet, it is important to be able to recognise FAD because it is possible to offer such kindreds definitive genetic counselling, provided that the causative mutation can be identified. Furthermore, a study by Campion et al (1999) suggests that FAD may occur at a frequency of around 40 per 100000 persons at risk, which implies that there are some 600 affected individuals to be found in England and Wales, a number that suggests that a psychiatrist or neurologist will encounter an individual from a FAD pedigree at some time in their working life.

\section{SUGGESTED APPROACH FOR HIGHLY FAMILIAL FORMS OF ALZHEIMER'S DISEASE}

The function of the psychiatrist is straightforward. The first step is to confirm that the diagnosis is actually one of Alzheimer's disease and not one of the other, often familial, dementias such as Huntington's disease, frontal-temporal dementias, Creutzfeldt-Jakob disease (CJD) or cerebral autosomal dominant arteriopathy with subcortical infarcts and leukoencephalopathy (CADASIL). Next, the clinician should take as detailed a family history as possible in order to try to determine whether the sufferer comes from a pedigree with autosomal dominant FAD: the occurrence of numerous individuals with early-onset disease ( $<55$ years) in several generations is highly suggestive. The presence of many affected individuals in one generation may also raise suspicion because it should not be forgotten that early death from other causes might prevent manifestation of the disorder in carriers of a disease gene. In practice, we recommend that families containing three members with a history of early-onset Alzheimer's disease occurring before the age of 60 years should, if they request advice, be referred to a clinical geneticist. Some forms of FAD linked to PSEN2 mutations occur after the age of 65 years, and so the psychiatrist should have a low threshold for discussing a pedigree with a clinical geneticist.

Predictive or prenatal testing is potentially feasible in families with FAD but will depend upon the availability of DNA from at least one affected individual in order to establish which mutation is causing disease in that family. It is worth stating that genetic counselling is a highly specialised area and it is strongly recommended that psychiatrists do not involve themselves without the appropriate training.

The study by Campion et al (1999) analysed DNA from 34 families with FAD (obtained from all over France) for causative mutations. Probably pathogenic mutations were found in the PSEN1 gene in 19 families, mutations within the APP gene in another 5 and no mutations in the PSEN1, PSEN2 or APP genes in the remaining 10 families. Thus, individuals from FAD pedigrees need to be informed that there is 
a $30 \%$ chance that, with the current state of our knowledge, no causative mutation will be found. If no mutation is found then, if the pedigree is strongly suggestive of an autosomal dominant disorder, the geneticist may choose to go on to search for mutations in genes associated with similar conditions - prion protein $(\mathrm{PrP})$ in CJD and tau in frontal-temporal dementias, for example. Yet another factor to consider is that there has been one report of apparent non-penetrance of a PSEN1 mutation in a healthy 68-year-old member of a FAD pedigree (Rossor et al, 1996). Notwithstanding these caveats, in the absence of any preventive treatment, the take-up for predictive testing is likely to be low, as has been the case in Huntington's disease (Binedell et al, 1998).

\section{SUGGESTED APPROACH FOR NON-MENDELIAN ALZHEIMER'S DISEASE}

The great majority of cases of Alzheimer's disease do not result from disease-causing mutations in a single gene. Here inheritance does not follow simple Mendelian ratios but appears to reflect the presence of a number of different genetic risk factors together with environmental factors.

When faced with someone who is worried about their risk of developing Alzheimer's disease it is often worth pointing out that we are all at some risk of developing Alzheimer's disease provided that we live long enough. The large Rotterdam study suggests that the risk at age 55 years of developing dementia in the following 35 years is 0.26 for a woman and 0.15 for a man (Ott et al, 1998). In this study 73\% of dementia was wholly or partially attributable to Alzheimer's disease. The large continuing Framingham study yields somewhat lower lifetime risks of Alzheimer's disease after the age of 65 years: $6.3 \%$ for men and $12 \%$ for women, with a corresponding risk for all dementia of $10.9 \%$ and $19 \%$, respectively (Seshadri et al, 1997). Many epidemiological studies suggest that women are at increased risk of Alzheimer's disease. The reasons for this are not clear, but increased longevity compared to men, increased survival with the disease and some increase in intrinsic vulnerability probably all play a part.

Prevalence studies tell us that dementia doubles every 5 years after the age of 65 years up to the age of around 85 years, after which time the rate of increase appears to slow (Heeren et al, 1991; Skoog et al,
1993; Ritchie \& Kildea, 1995; Breitner et al, 1999; von Strauss et al, 1999). It is likely that some of this slowing is due to very old people not living as long with their dementia as younger sufferers do, although it is also possible that survivors into late old age are relatively resistant to developing dementia (Drachman, 1994). Prevalence data are summarised in Table 1.

In fact, two nearly completely ascertained community-based studies, one from Japan and one from The Netherlands, found that the prevalence of dementia in centenarians was very high: $70 \%$ in the Japanese and $88 \%$ in the Dutch sample (Asada et al, 1996; Blansjaar et al, 2000). Asada et al (1996) attributed some $76 \%$ of the dementia to Alzheimer's disease and demonstrated that the 6-month mortality rate was $27 \%$ for the centenarians with dementia, whereas none of the non-demented centenarians died.

Thus, prevalence figures for dementia tell us that many of us are at some risk of developing dementia, provided that we live long enough. This is obviously too simplistic: most people do not expect to live into their mid-90s; a much more reasonable question is, "What is my chance of developing Alzheimer's disease by the age of 85 years?". Family studies in Alzheimer's disease can go some way towards allowing us to answer this question for the relatives of affected individuals.

\section{FAMILY STUDIES AND RISK OF DEMENTIA}

In the 1980 s and early 1990 s there were a number of family studies that attempted to identify the inheritance pattern of Alzheimer's disease and to quantify the risk to first-degree relatives in families with a history of Alzheimer's disease, in comparison with family members of control

Table I Prevalence of dementia by age (from Ritchie \& Kildea, 1995, with permission)

\begin{tabular}{lc}
\hline Age (years) & Prevalence of dementia (\%) \\
\hline $65-69$ & 1.5 \\
$70-74$ & 3.5 \\
$75-79$ & 6.8 \\
$80-84$ & 13.6 \\
$85-89$ & 22 \\
$90-94$ & 32 \\
$95-99$ & 45 \\
\hline
\end{tabular}

individuals (summarised in McGuffin et al, 1994). There have also been a few studies based on more representative community samples.

Overall, the findings from studies based in memory clinics (that are likely to be centres of secondary referral) suggest that $30-48 \%$ of probands with Alzheimer's disease have a history of affected firstdegree relatives compared with $13-19 \%$ of controls. This translates to $6-14 \%$ of the relatives of patients with Alzheimer's disease having a history of Alzheimer's disease compared with $3.5-7 \%$ of the first-degree relatives of healthy controls. Kaplan-Meier life table analysis has been used in these studies to infer that the cumulative risk of dementia by age 90 varies between 30 and $50 \%$ compared with between 10 and $23 \%$ in control relatives. However, as has been pointed out by Breitner, owing to competing causes of death, only about one-third of this theoretical familial predisposition to Alzheimer's disease is realised in the usual life span. This translates to an actual predicted risk of developing Alzheimer's disease in the first-degree relatives of probands with Alzheimer's disease of 15-19\%, compared with 5\% in controls (Breitner et al, 1988; Breitner, 1991).

The latest systematically ascertained twin studies on the heritability of Alzheimer's disease also tend to support the estimates of familial risk derived from family studies. Probandwise, concordance rates of about $40 \%$ and $84 \%$, respectively, are seen in fraternal and identical twins (Bergem et al, 1997). Because fraternal twins are genetically equivalent to ordinary firstdegree relatives, the observed morbid risk of developing Alzheimer's disease is similar to that estimated for first-degree relatives in family studies.

A study by Silverman et al (1994) suggested that, in large measure, the familial component of risk to the relatives of probands with Alzheimer's disease was expended by the end of the ninth decade, after which time the risk was very similar to that in controls. A number of other family history studies have suggested that familial factors are more prominent when onset is earlier (McGuffin et al, 1994). Thus, much of Alzheimer's disease in late old age may be considered as not very familial and merely an expression of one of the ways in which the ageing process is manifested in those few survivors into late old age.

The findings from these family studies can be used to advise relatives in only the 
broadest terms. One can do little more than to say that, on balance, the risk to the firstdegree relatives of patients with Alzheimer's disease who developed the disorder at any time up to the age of 85 years is increased some threefold to fourfold relative to the risk in controls. This would seem to translate to a risk of developing Alzheimer's disease of between one in five and one in six, which, although an improvement on a risk of one in two, can still be rather frightening. In order to put this risk into better perspective, and to help allay the client's anxiety, it may be preferable to present the risk estimates in a graphical form, as is done in Fig. 1 (from Breitner et al, 1988). If this is done, clients can see that even at 78 years, the age of greatest risk, the actual predicted risk is only some $3 \%$ and that the cumulative risk (half the area under the curve $f(x) \cdot S(x)$ ) from age 65 to 78 is probably less than $10 \%$. In our experience many tell us that this is reassuring-partly because their worries were about getting Alzheimer's disease in their fifties "because this is when familial Alzheimer's disease happens" or in their sixties/seventies, thus preventing them from enjoying retirement.

In the case of patients with Alzheimer's disease who became demented late in old age, say by their 80 s, relatives probably run the same $30-50 \%$ risk of developing dementia as anyone else who lives to the age of 90 years and beyond. Of course, it is possible that some of the same genes that confer longevity may also increase the risk of developing Alzheimer's disease. Like other disorders that reflect the combined action of several genes, the risk to relatives drops rapidly as the degree of genetic relatedness falls. Data are limited but the risk

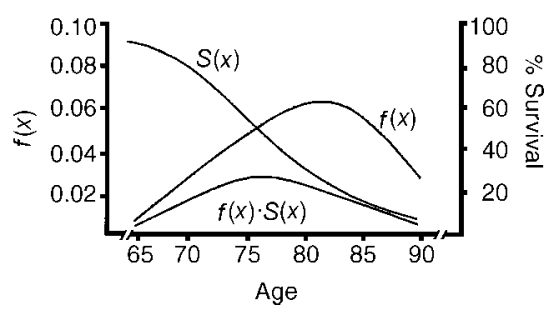

Fig. I $f(x)$ represents the probability of a hypothetical relative of a patient with Alzheimer's disease developing Alzheimer's disease at age $x$ in the absence of any competing form of mortality. $S(x)$ represents the actuarial probability of surviving to age $x$. The product of $f(x) \cdot S(x)$ represents the probability of the relative surviving to age $x$ and developing Alzheimer's disease. Adapted from Breitner et al (1988) to second-degree relatives, such as grandchildren, is probably less than twice the population levels (Heston et al, 1981).

\section{THE APOLIPOPROTEIN E EFFECT}

Apolipoprotein E (apoE) is a protein with roles in lipid metabolism and tissue repair. Its primary site of biosynthesis is the liver, but the second major site of synthesis is the brain. Like APP, the synthesis of apoE is up-regulated after the nervous system has been damaged. There are three commonly occurring polymorphic forms of apoE, known as apoE2, apoE3 and apoE4, which originate from the APOE $\varepsilon 2$, APOE $\varepsilon 3$ and APOE $\varepsilon 4$ alleles of the gene. The key observation, originally made by Strittmatter et al (1993), is that the frequency of APOE $\varepsilon 4$ in patients with Alzheimer's disease (namely $0.3-0.5$ ) is greater than the APOE $\varepsilon 4$ frequency of $0.1-0.15$ in age-matched or population controls. Some studies suggest that the APOE $\varepsilon 2$ allele is underrepresented in Alzheimer's disease and may, by inference, be protective (reviewed by Farrer et al, 1997). Consistent with this idea is the finding that healthy centenarians have a higher APOE $\varepsilon 2$ frequency than general population controls (Schächter et al, 1994; Kehoe et al, 1999).

The APOE $\varepsilon 4$ association with Alzheimer's disease has been replicated in many laboratories around the world. A meta-analysis summarised the data and demonstrated that the association was found in people of European, African American, American Hispanic and Japanese origin (Farrer et al, 1997). Exactly how APOE $\varepsilon 4$ and the apoE4 protein influence the pathophysiology of Alzheimer's disease is still unknown, but bearers of this risk allele appear to get Alzheimer's disease earlier and develop a heavier amyloid burden.

\section{CLINICAL SIGNIFICANCE OF APOLIPOPROTEIN E GENOTYPE}

Most studies show that patients with Alzheimer's disease having APOE $\varepsilon 4$ deteriorate no more rapidly than those without this allele (Corder et al, 1995; Growdon et al, 1996; Holmes et al, 1996; Kurz et al, 1996; Stern et al, 1997). It is possible that APOE $\varepsilon 4$ is a marker for a poor response to treatment with acetylcholinesterese inhibitors, particularly, perhaps, in women (Poirer et al, 1995; Farlow et al, 1998).

The consensus of opinion appears to be that APOE genotype determines 'when' rather than 'whether' one succumbs to Alzheimer's disease. For example, the Cache County study (Meyer et al, 1998, Breitner et al, 1999) on an elderly population of almost 5000 found 22 cases of Alzheimer's disease among 141 APOE $\varepsilon 4$ homozygotes, 118 among 1452 APOE $\varepsilon 4$ heterozygotes and 80 among 3339 not bearing the APOE $\varepsilon 4$ allele. There appeared to be a plateau in each group's survival curve beyond which no new cases of Alzheimer's disease were seen. For APOE $\varepsilon 4$ homozygotes no new cases were seen after the age of 84 years, with nine individuals surviving without Alzheimer's disease for a combined total of a further 37 years. For APOE $\varepsilon 4$ heterozygotes the last onset of Alzheimer's disease was at 99 years, with four long-term survivors. The last onset of dementia in individuals without the APOE $\varepsilon 4$ allele was at age 95 years, with 31 surviving free of dementia for a combined total of 100 years thereafter. This differential effect of APOE genotype on the age of maximum risk of Alzheimer's disease is also suggested in the APOE meta-analysis of Farrer et al (1997) and also in the study by Asada et al (1996).

A Bayesian analysis has been used by Seshadri et al (1995) to relate the APOE genotype to the lifetime risk of developing Alzheimer's disease. When the estimates of dementia risk derived from the Framingham study (Seshadri et al, 1997) are substituted in the analysis, somewhat lower risk estimates, which are stratified according to gender, are obtained (Table 2).

These estimates suggest that, at most, some $50 \%$ of APOE $\varepsilon 4$ homozygotes will develop Alzheimer's disease within their lifetime. These predictions agree well with the general population-based study of Henderson et al (1995), which suggested that

Table 2 Remaining lifetime risk at age 65 years of developing Alzheimer's disease according to gender and apolipoprotein E (APOE) status

\begin{tabular}{lcc}
\hline APOE status & Male (\%) & Female (\%) \\
\hline APOE \&4 status unknown & 6.3 & 12 \\
No APOE \&4 & 4.6 & 9.3 \\
APOE \&4 heterozygote & 12 & 23 \\
APOE \&4 homozygote & 35 & 53 \\
\hline
\end{tabular}


the risk of developing dementia by age 90 years in APOE $\varepsilon 4$ homozygotes was about $50 \%$.

\section{POSSIBLE CLINICAL USES OF APOE GENOT YPING IN ALZHEIMER'S DISEASE}

From the foregoing it is obvious that knowledge of a person's APOE genotype is of little more use in predicting their chances of succumbing to Alzheimer's disease than is knowledge of their family history of dementia. It seems that even individuals with the APOE $\varepsilon 4 / \mathrm{APOE} \varepsilon 4$ genotype have, on average, a greater than $50 \%$ chance of escaping the disease. Therefore, APOE genotyping currently has no role in predicting the risk of developing Alzheimer's disease.

Some claims have been made that APOE genotyping may be an aid to diagnosing Alzheimer's disease. The study by Mayeux et al (1998) suggested that for patients referred to specialised assessment centres for Alzheimer's disease, APOE genotyping used in combination with clinical criteria might improve the specificity of the diagnosis. The data show that whereas the demonstration of one or more APOE $\varepsilon 4$ allele in a person suspected of suffering with dementia slightly increases the accuracy of a clinical diagnosis of Alzheimer's disease, the absence of an APOE $\varepsilon 4$ allele has little value in either endorsing or refuting a clinical diagnosis of Alzheimer's disease. Thus, even in a selected group of patients, presumably all with a high a priori chance of Alzheimer's disease, APOE genotyping seems to confer negligible diagnostic benefit.

\section{GENETIC COUNSELLING AND ALZHEIMER'S DISEASE}

A number of groups in the UK and in the USA have formulated consensus guidelines regarding genetic testing and genetic counselling in Alzheimer's disease, including Alzheimer's Disease International (Brodaty et al, 1996), the American College of Medical Genetics/American Society of Human Genetics Working Group on APOE and Alzheimer's Disease (Farrer et al, 1995) and the Alzheimer's Association/National Institute of Aging (Davies et al, 1998). In the UK, the Alzheimer's Disease Genetics Consortium meets regularly to discuss the issues surrounding the clinical use of genetics in Alzheimer's disease. These issues include not only whether to test, but how to counsel patients and issues regarding confidentiality and consent, research ethics and concerns regarding insurance (Tunstall \& Lovestone, 1999). The various groups that have drawn up the following consensus guidelines are generally of one mind with regard to the clinical response to our growing understanding of the genetics of Alzheimer's disease.

(a) Families where there is evidence of FAD (or indeed any familial early-onset dementia) should be referred to a specialist centre - in the UK this will be a regional genetics department.

(b) Counselling for such families should follow the process established for Huntington's disease.

(c) For late-onset Alzheimer's disease all the groups are agreed that there is no role for APOE genotyping in prediction or risk assessment.

\section{RECOMMENDATIONS}

\section{Apparent FAD}

Early-onset familial dementia is straightforward-refer to a regional genetics department.

\section{Late-onset Alzheimer's disease}

For late-onset Alzheimer's disease there is wide agreement that there is no genetic test available, but genetic testing is not the same as genetic counselling. The absence of a test should not mean that relatives are denied information and the opportunity to discuss their concerns. So, when asked "am I likely to get Alzheimer's disease?" by the relative of a patient with late-onset Alzheimer's disease, how should one answer? In most cases of Alzheimer's disease it is only possible to advise relatives of their risk in the broadest terms. Extrapolating from family history studies, it is possible to say that the risk to the children is in the region of one in five to one in six and one should be prepared to illustrate what this means in an easy to understand graphical form. We believe that it is permissible for such a broad estimate of risk to be imparted by a consultant or doctor not specifically trained in genetic counselling.

Occasionally, psychiatrists encounter families with several siblings affected by late-onset Alzheimer's disease and a history of dementia in previous generations. Such families almost certainly exhibit high genetic loading, but there are few reliable data on whether and to what extent risk increases with the number of affected relatives, although studies of other common disorders suggest that this is likely to be the case. However, it should be borne in mind that the number of affected relatives may well depend on factors affecting longevity as well as on the degree of genetic loading for Alzheimer's disease, and it may not be advisable or possible to base discussion on risk estimates that are increased when several relatives have been affected in late old age. There is also preliminary evidence for substantially increased risk in the offspring of parents who both have a diagnosis of Alzheimer's disease (Bird et al, 1993). In such pedigrees, if relatives request further information, it may be worth taking a detailed family history and consulting with a clinical geneticist.

\section{ACKNOWLEDGEMENT}

Our work is supported by a Medical Research Council cooperative group grant.

\section{REFERENCES}

Asada, T., Yamagata, Z., Kilnoshita, T., et al (1996) Prevalence of dementia and distribution of ApoE alleles in Japanese centenarians: an almost-complete survey in Yamanashi Prefecture, Japan. Journal of the American Geriatrics Society, 44, I5I-155.

Bergem, A. L. M., Engedal, K. \& Kringlen, E. (1997) The role of heredity in late-onset Alzheimer's disease and vascular dementia. Archives of General Psychiatry, 54, 264-270.

Binedell, J., Soldan, J. R. \& Harper, P. S. (1998)

Predictive testing for Huntington's disease: I. Predictors of uptake in South Wales. Clinical Genetics, 54, 477-488.

Bird, T. D., Nemens, E. J. \& Kukull, W. A. (1993) Conjugal Alzheimer's disease: is there an increased risk in offspring? Annals of Neurology, 34, 396-399.

Blansjaar, B. A., Thomassen, R. \& van Schaick, H.W. (2000) Prevalence of dementia in centenarians. International Journal of Geriatric Society, $\mathbf{1 5}$, 219-225.

Breitner, J. C. S. (199I) Clinical genetics and genetic counselling in Alzheimer's disease. Annals of Internal Medicine, II5, 60I-606

_ , Murphy, E. A., Silverman, J. M., et al (1988) Agedependent expression of familial risk in Alzheimer's disease. American Journal of Epidemiology, $\mathbf{1 2 8}$, 536-548.

_ , Wyse, B. W., Anthony, J. C., et al (1999) APOE- $\varepsilon 4$ count predicts age when prevalence of AD increases, then declines: the Cache County Study. Neurology, 53 $32|-33|$

Brodaty, H., Conneally, M., Gauthier, S., et al (1996) Medical and scientific committee Alzheimer's Disease International consensus statement on predictive testing. Alzheimer's Disease and Associated Disorders, 9, 182-187. 
Campion, D., Dumanchin, C., Hannequin, D., et al (1999) Early-onset autosomal dominant Alzheimer's disease: prevalence, genetic heterogeneity, and mutation spectrum. American Journal of Human Genetics, 65, 664-670.

Corder, E. H., Saunders, A. M., Strittmatter, W. J., et al (1995) Apolipoprotein E, survival in Alzheimer's disease patients, and the competing risks of death and Alzheimer's disease. Neurology, 45, 1323-1328.

Drachman, D. A. (1994) If we all live long enough, will we all be demented? Neurology, 44, I563-1565.

Davies, P., Gilman, S., Growdon, J. H., et al (1998) Consensus report of the working group on 'Molecular and Biochemical Markers of Alzheimer's Disease'. Neurobiology of Aging, 19, 109-116.

Farlow, M. R., Lahiri, D. K., Poirer, J., et al (1998) Treatment outcome of tacrine therapy depends on apolipoprotein genotype and gender of the subjects with Alzheimer's disease. Neurology, 50, 669-677.

Farrer, L. A., Brin, M. F., Elsas, L., et al (1995) The American College of Medical Genetics and American Society of Human Genetics: statement on the use of apolipoprotein E testing for Alzheimer's disease. Journal of the American Medical Association, 274, 1627-1629.

_ , Cupples, L. A., Haines, J. L., et al (1997) Effects of age, sex, and ethnicity on the association between apolipoprotein E genotype and Alzheimer's disease: a meta-analysis. Journal of the American Medical Association, 278, 1349-1356.

Growdon, J. H., Locascio, J. J., Corkin, S., et al (1996) Apolipoprotein E genotype does not influence rates of cognitive decline in Alzheimer's disease. Neurology, 47 , 444-448.

Heeren, T. J., Lagaay, A. M., Hijmans, W., et al (199I) Prevalence of dementia in the 'oldest old' of a Dutch community. Journal of the American Geriatrics Society, 39 755-759.

Henderson, A. S., Easteal, S., Jorm, A. F., et a (1995) Apolipoprotein E allele $\varepsilon 4$, dementia, and cognitive decline in a population sample. Lancet, 346 1387-1390

Heston, L. L., Mastri, A. R., Anderson, E., et al (198I) Dementia of the Alzheimer type: clinical genetics, natural history, and associated conditions. Archives of General Psychiatry, 38, 1085-1090.

Holmes, C., Levy, R., McLoughlin, D. M., et al (1996) Apolipoprotein $\mathrm{E}$ and the clinical features of late onset Alzheimer's disease. Journal of Neurology, Neurosurgery and Psychiatry, 61, 580-583.

Kehoe, P., Russ, C., Mcllroy, S., et al (1999) Variation in DCPI, encoding ACE, is associated with susceptibility to Alzheimer's disease. Nature Genetics, 2I, 7I-72.

Kurz, A., Egensperger, R., Haupt, M., et al (1996) Apolipoprotein E $\varepsilon 4$ allele, cognitive decline, and deterioration of everyday performance in Alzheimer's disease. Neurology, 47, 440-443.

Mayeux, R., Saunders, A. M., Shea, S., et al (1998) Utility of the apolipoprotein E genotype in the diagnosis of Alzheimer's disease. New England Journal of Medicine, 338, 506-5II.

Meyer, M. R., Tschanz, J-A.T., Norton, M. C., et al (1998) APOE genotype predicts when - not

whether - one is predisposed to develop Alzheimer's disease. Nature Genetics, 19, 321-322.

McGuffin, P., Owen, M. J., O'Donovan, M. C., et al (1994) Seminars in Psychiatric Genetics. London: Gaskell.

\section{CLINICAL IMPLICATIONS}

- The taking of a family history to look for other cases of dementia in first-degree relatives should be part of every routine dementia diagnostic process.

- A clinician should be able to recognise possible familial Alzheimer's disease and be able to refer the family on to a regional genetics centre if members of the family request genetic counselling.

- A clinician should be able to advise relatives from less highly genetically loaded pedigrees with Alzheimer's disease about their risk in broad terms and seek advice from a regional genetics centre if further clarification is required.

\section{LIMITATIONS}

- In the interests of space and clarity, citation of the literature is selective.

- Estimates of risk are in some instances approximate and may need to be modified in the light of future work.

- Few data relating to vascular and mixed forms of dementia are available.

M. B. LIDDELL, MRCPsych, Department of Psychological Medicine, University of Wales College of Medicine, Cardiff; S. LOVESTONE, MRCPsych, Institute of Psychiatry, London; M. J. OWEN, FRCPsych, Department of Psychological Medicine, University of Wales College of Medicine, Cardiff

Correspondence: Dr M. B. Liddell, Department of Psychological Medicine, University of Wales College of Medicine, Heath Park, Cardiff CFI4 4XN, UK. E-mail: liddellmb@cardiff.ac.uk

(First received 14 February 2000, final revision 26 June 2000, accepted 28 June 2000)

Ott, A., Bretelar, M. M. B., van Harskamp, F., et al (1998) Incidence and risk of dementia: the Rotterdam study. American Journal of Epidemiology, 147, 574-580.

Poirier, J., Delisle, M.-C., Quirion, R., et al (1995) Apolipoprotein E4 alleles as a predictor of cholinergic deficits and treatment outcome in Alzheimer's disease. Proceedings of the National Academy of Sciences USA, 92 1260-1264.

Ritchie, K. \& Kildea, D. (1995) Is senile dementia age related' or ageing-related? Evidence from meta-analysis of dementia prevalence in the oldest old. Lancet, $\mathbf{3 4 6}$ 931-934

Rossor, M. N., Fox, N. C., Beck, J., et al (1996) Incomplete penetrance of familial Alzheimer's disease in a pedigree with a novel presenilin-I gene mutation. Lancet, 347, 1560.

Schächter, F., Faure-Delanef, L., Guénot, F., et al (1994) Genetic associations with human longevity at the APOE and ACE loci. Nature Genetics, 6, 29-32.

Selkoe, D. J. (1999) Translating cell biology into therapeutic advances in Alzheimer's disease. Nature, 399 (suppl.), A23-A31.

Seshadri, S., Drachman, D. A. \& Lippa, C. F. (1995) Apolipoprotein $\mathrm{E} \varepsilon 4$ allele and the lifetime risk of Alzheimer's disease: what physicians know and what they should know. Archives of Neurology, 52, 1074-1079.
_ Wolf, P. A., Beiser, A., et al (1997) Lifetime risk of dementia and Alzheimer's disease: the impact of mortality on risk estimates in the Framingham study. Neurology, 49, 1498-1504.

Silverman, J. M., Ge, L., Zaccarto, M. L., et al (1994) Patterns of risk in first-degree relatives of patients with Alzheimer's disease. Archives of General Psychiatry, 5I, 577-586.

Skoog, I., Nilsson, L., Palmertz, B., et al (1993) A population-based study of dementia in 85-year olds. New England Journal of Medicine, 328, 153-158.

Stern, Y., Brandt, J., Albert, M., et al (1997) The absence of an apolipoprotein $\varepsilon 4$ allele is associated with a more aggressive form of Alzheimer's disease. Annals of Neurology, 4I, 615-620.

Strittmatter, W. J., Saunders, A. M., Schmechel, D. et al (1993) Apolipoprotein $E$ : high-avidity binding to $\beta$ amyloid and increased frequency of type 4 allele in lateonset familial Alzheimer's disease. Proceedings of the National Academy of Sciences USA, 90, 1977-1981.

Tunstall, N. \& Lovestone, S. (1999) The UK Alzheimer's disease genetics consortium. International Journal of Geriatric Psychiatry, 14, 789-79|.

von Strauss, E., Viltanen, M., De Ronchi, D., et al (1999) Ageing and the occurrence of dementia: findings from a population-based cohort with a large sample of nonagenarians. Archives of Neurology, 56, 587-592. 